\title{
Viral quantity and pathological changes in broilers experimentally infected by IRFIBV32 isolate of infectious bronchitis virus
}

\author{
Ali Mohammadi ${ }^{1} \cdot$ Keramat Asasi $^{2} \cdot$ Zahra Boroomand $^{2,4} \cdot$ Fatemeh Namazi $^{3}$. \\ Seyedeh Alemeh Hosseinian ${ }^{2}$
}

Received: 14 August 2015/ Accepted: 2 November 2015/Published online: 12 November 2015

(C) Indian Virological Society 2015

\begin{abstract}
An Iranian isolate of avian infectious bronchitis virus IRFIBV32 was quantified in experimentally infected broilers using real-time reverse transcriptase polymerase chain reaction and histopathological changes was investigated. Thirty-six 3-week-old commercial broilers were inoculated by $10^{5}$ ELD50/0.1 $\mathrm{ml}$ of the virus. On the various days post inoculation (dpi) different tissues were collected. The virus strongly started the replication in trachea at $1 \mathrm{dpi}$ and reached to the maximum titer at $3 \mathrm{dpi}$. The highest IBV RNA level was shown in this organ. In lung, the virus was replicated with the titer lower than that of the trachea, but it rose up more at 5 dpi. The kidneys were the tissues with the least viral genome copy number, although the duration of the virus presence was considerable. The virus replicated in testes sooner than ovaries also disappeared sooner but the maximum viral yield in the ovaries was more. The virus titer in the studied tissues had an interesting fluctuation especially in caecal tonsils. Testes and ovaries were the organs that the virus could reactivate without using any chemical. The most severe lesions were observed in tracheae but they appeared in the
\end{abstract}

Ali Mohammadi

mohammad@shirazu.ac.ir

1 Division of Virology, Department of Pathobiology, School of Veterinary Medicine, Shiraz University, Shiraz 71345-1731, Iran

2 Division of Avian Medicine, Department of Clinical Sciences, School of Veterinary Medicine, Shiraz University, Shiraz, Iran

3 Division of Pathology, Department of Pathobiology, School of Veterinary Medicine, Shiraz University, Shiraz, Iran

4 Present Address: Department of Avian Medicine, School of Veterinary Medicine, Shahid Chamran University of Ahvaz, Ahvaz 61357-83151, Iran lungs later. Lymphocyte infiltration in the kidneys was noted from 5 dpi even sooner than the lungs. There were no lesions in the caecal tonsils, testes and ovaries in spite of the virus replication in a high titer.

Keywords Chicken · IBV - Real time RT PCR · Quantitation · Pathology

Infectious bronchitis (IB) is an acute, highly contagious upper respiratory disease of chickens. IB is characterized by tracheal rales, sneezing and coughing, increased oculo-nasal secretion and excess mucus in the trachea accompanied by decreases in both weight gain and feed efficiency. Economic consequences to the poultry industry comprise growth retardation and high morbidity and mortality rates in meattype birds. In addition, reduced egg production, decreased internal, external egg quality, hatchability and fertility have been documented in layers and breeders [8]. This disease is caused by infectious bronchitis virus (IBV), a member of the family Coronaviridae (order Nidovirales) and genus Coronavirus [6]. IBV has been shown to replicate in many respiratory tissues including trachea, lungs, and air sacs, causing respiratory infection; in some urogenital tissues such as kidney, testes and oviduct, causing minor or major nephritis; and in many parts of the alimentary tract as well [12]. Live attenuated and inactivated vaccines have been developed to control IB. Despite extensive vaccination, IB has been a perpetual problem in the Iranian poultry industry since the disease was first reported in 1994 [2, 18]. A new isolate of IB virus (IRFIBV32) from broiler chicken in Fars province, Southern Iran, is isolated and identified by Boroomand et al. [6]. Furthermore, the tissue distribution and clinical signs of experimentally infected chicks by this isolate are also studied [5]. 
Currently, Real time reverse transcription polymerase chain reaction (RRT PCR) technique has been developed and used widely for rapid, sensitive and accurate diagnosis of different diseases. A RRT PCR test has been developed using a Taqman probe for the detection of American strains of IBV from tracheal swabs [7] and a locked nucleic acid (LNA) probe-based RRT PCR assay for the detection of the Australian IBV strains [10]. Jackwood et al. [14] used a RRT PCR diagnostic test with the use of fluorescence resonance energy transfer (FRET) technology to detect several common strains of IBV. In this study, we identified IBV load in different tissues of experimentally infected broilers to clarify the replication strength of IRFIBV 32 Isolate at intervals post challenge. This was achieved using TaqMan ${ }^{\circledR}$-labeled probe two-step RRT PCR assay targeting the $\mathrm{N}$ gene of the virus. The $\mathrm{N}$ gene was chosen since it is highly conserved among IBV strains. We believe that the quantitation of the virus in different organs of the infected bird at different times post virus inoculation accompanied with pathological study may further help us to investigate the virus pathogenesis.

The virus isolate used in this study was IRFIBV32 (GenBank: HQ123359.1). Some characteristics of the isolate reported previously [6]. Virus propagation was performed in 10-day-old embryonated chicken eggs, as described previously [17]. The embryo lethal dose $\left(\operatorname{ELD}_{50}\right)$ of infected allantoic fluid was calculated according to the Reed and Muench [17] method. In the present study, allantoic fluid containing $10^{5} \mathrm{ELD}_{50} / 0.1 \mathrm{ml}$ of the virus was used to induce the infection. Fifty-nine apparently healthy 1-day-old Ross broiler chicks were divided randomly into two experimental groups comprising group 1 (challenged group: $\mathrm{n}=41$ ) and group 2 (control group: $\mathrm{n}=18$ ). Two groups of chicks were reared separately in the Animal Research Unit of the Veterinary School of Shiraz University and received feed and water ad libitum during the experiment. All experiments were conducted after institutional approval of the animal use committee of Shiraz University. Prior to challenge, five birds from the experimental group (group 1) were killed and their organs were investigated for IBV detection. At 20 days old, all birds in group 1 was challenged intranasally with $100 \mu \mathrm{l}$ allantoic fluid containing $10^{5}$ ELD50 of the virus. The chicks in group $2 \mathrm{kept}$ as unchallenged control. All the chicks were monitored daily for 20 days for clinical signs, and mortality. On 1, 2, 3, 5, 7, 11, 13, 15 and 20 days post inoculation (dpi) four birds from the challenged group and two birds from the control group were randomly selected. Then, they were bled for plasma separation and sacrificed for collecting tissue samples. Gross lesions were recorded and their trachea, lungs, kidneys, caecal tonsils, testes and ovaries were aseptically collected separately for the virus detection, titration and histopathological evaluations. All tissue samples were immediately frozen and stored at $-70{ }^{\circ} \mathrm{C}$ until needed for the RNA extraction. The samples for histopathological evaluations were fixed in $10 \%$ neutral buffered formalin, embedded in paraffin and the sections were stained with haematoxylin and eosin and studied by an ordinary light microscope. RNA extraction from clinical samples was performed with the Accuzol ${ }^{\mathrm{TM}}$ (BioNeer Corporation, South Korea) according to the manufacturer's protocol. Appropriate amount of plasma $(250 \mu \mathrm{l})$ or homogenized tissues $(50-100 \mathrm{mg}$ ) were used for the extraction. Isolated RNAs were solved in a final volume of $50 \mu \mathrm{l}$ distilled water (DW) and was quantified by spectrophotometry. Appropriate RNase Inhibitor and DNase (Fermentas) were added and stored at $-70{ }^{\circ} \mathrm{C}$ until assayed. For standard preparation, $100 \mu \mathrm{l}$ infected allantoic fluid was used for RNA extraction and cDNA synthesis was carried out using BIONEER RT-premix kit according to the manufacturer's instructions. PCR was performed to amplify $276 \mathrm{bp}$ fragment of $\mathrm{N}$ protein gene of IBV that included in the RRT PCR assay amplicons [1]. Five microliter of total RNA and 10 pmol of antisense primer were used for cDNA preparation. Three microliter of cDNA were added to $22 \mu \mathrm{l}$ PCR master mix containing: $2.5 \mu \mathrm{l} 10 \mathrm{X}$ PCR buffer, $0.75 \mu \mathrm{MgCl}_{2}(50 \mathrm{mM}), 0.5 \mu \mathrm{l}$ dNTPs $(10 \mathrm{mM}), 10$ pmol of each primer, $15.75 \mu \mathrm{l}$ DNase/ RNase free DW and $0.5 \mu 1$ Taq DNA Polymerase (5 IU/ $\mu \mathrm{l})$. The program in Ependorf thermal cycler was $95^{\circ} \mathrm{C}$ for 3 min and 35 cycles including: $95^{\circ} \mathrm{C}$ for $45 \mathrm{~s}, 55.6^{\circ} \mathrm{C}$ for $45 \mathrm{~s}, 72{ }^{\circ} \mathrm{C}$ for $50 \mathrm{~s}$ and a final extension step at $72{ }^{\circ} \mathrm{C}$ for $7 \mathrm{~min}$. The PCR products were separated in a $1 \%(\mathrm{w} / \mathrm{v})$ agarose gel and visualized under ultraviolet light after staining with ethidium bromide. PCR products (276 bp) was cloned into a T-vector (pTZ57R/T) based on Fermentas I nsTAcloneTMPCR cloning kit instructions. The plasmid DNA was amplified in E. coli strain GM2163 and purified using BIONEER Accuprep Plasmid Extraction kit. The recombinant plasmid was verified by DNA sequencing. The concentration of the plasmid DNA was calculated using spectrophotometery. Recombinant plasmids were serially diluted tenfold as a standard in the RRT PCR. The cDNA synthesis from normalized RNA of the samples was carried out and then RRT PCR was performed using a mixture of 20 pmol random hexamer and 20 pmol of reverse primer [1]. The RRT PCR primers and TaqMan probe used in this study were described previously by Chousalkar et al. [10]. The assays were performed in the BIO-RAD MiniOpticonTM System. The reaction mixture contained $5 \mu \mathrm{l}$ of target cDNA, $1 \mu \mathrm{l}$ of each primer and probe at concentration of $10 \mathrm{pmol} / \mu \mathrm{l}, 10 \mu \mathrm{l}$ of $2 \mathrm{x}$ master mixes, $0.2 \mu \mathrm{l}$ of UNG (Uracil-N-Glycosylase), and $1.8 \mu \mathrm{l}$ of DW in a final volume of $20 \mu \mathrm{l}$. UNG treatment and two step cycles program were as previous [10]. Viral RNA copy numbers (expressed as copies per $1 \mu \mathrm{g}$ of total RNA) 
were quantified by comparison with a tenfold serially diluted recombinant plasmid standard of known concentration.

The quantity of the virus RNA in various organs of the challenged birds at the different dpi was determined by RRT PCR. All organs of the five birds killed at 0 dpi (prior to challenge) were negative for viral RNA. The results showed that the plasma samples of the challenged chickens were negative for the virus in any times post inoculation. The load of the virus in various tissues after challenge was shown in Table 1. The virus had its highest load in trachea on 3 dpi meanwhile lungs had the maximum level of the virus on $5 \mathrm{dpi}$. The virus existed at both organs up to 13 dpi. It was interesting that the titers on 13 dpi were more than those on $11 \mathrm{dpi}$. Although the viral titer in kidneys was lower than the other tissues, the duration of virus replication was considerable (up to $15 \mathrm{dpi}$ ). The maximum viral load in this organ was on $7 \mathrm{dpi}$. There was no any evidence for virus replication in the ovary up to 3 dpi but it was appeared on 5 dpi with the highest level. Although the virus was absent on $15 \mathrm{dpi}$, it was seen on 20 dpi again. Testes were the organs that the virus replicated very soon and it was continued till $11 \mathrm{dpi}$ with the highest level on 3 dpi. Caecal tonsils were the tissues with the highest duration of the virus replication and a considerable amount of the viral RNA. The maximum yield was seen on $5 \mathrm{dpi}$. It was the unique tissue that not only viral replication extended in all days but also there was an interesting fluctuation in the viral titer in the different days. The quantity of the viral RNA was remarkable even in the last day of the assay (Table 1). No virus was detected in samples from unchallenged birds, indicating that biosecurity precautions were adequate.

Histopathological examination of the tracheal sections showed loss of cilia, and degenerative changes in the epithelial cells, decreased goblet cells and mucus glands with infiltration of plasma cells and lymphocytes into the lamina propria from 1 to $9 \mathrm{dpi}$. On 11, 15 and $20 \mathrm{dpi}$, no changes were recorded in sections of trachea. Infiltration of mononuclear cells and interstitial pneumonia was evident in these chicks on 7 and 9 dpi. The kidney lesions consisted of infiltration of lymphocytes in the interstitial space. The lesions were seen from 5 to $20 \mathrm{dpi}$. There were no lesions in the caecal tonsils, testes and oviducts. Also no lesions were found in the tissue sections of the control animals.

IBV infection in chickens is known to be initiated by replication in the upper respiratory tract, which is usually restricted to the ciliated and mucus secreting cells of the nostrils, Harderian gland, trachea, lungs, and air sacs. Different type of IBV shows different tissue tropisms [5]. The maximum amount of viral RNA in the trachea was observed on $3 \mathrm{dpi}$, while that for lung was at $5 \mathrm{dpi}$. The viral RNA in trachea was not detected at 15 dpi therefore; the tracheal epithelium can support a finite amount of the virus. It is generally believed that upper respiratory tract is the primary site of IBV infection, although IBV can also replicate in the reproductive, renal, and digestive systems [8]. Callison et al. [7] detected the maximal load of viral RNA in the trachea at 5 dpi. Mahdavi et al. [15] detected increasingly viral antigen in the lung and tracheal epithelium cells from 2 to 5 dpi. Grgíc et al. [13] found that histological lesions were very prominent in the trachea during the first 6-7 days after exposure to IBV while, in the present study, tracheal lesions were seen from 1 to $7 \mathrm{dpi}$. In histopathological examination, tissue lesions including loss of cilia and degenerative changes in the epithelial cells, decreased mucus glands and mononuclear cells infiltration in sections of trachea, interstitial pneumonia and interstitial nephritis are consistent with previous studies [10]. As the isolate IRFIBV32 was able to replicate in trachea for a longer duration, it may be a reason for severity of its virulence.
Table 1 Copy numbers of IBV genome per $1 \mu \mathrm{g}$ of total RNA in different infected tissues of chickens at different dpi

\begin{tabular}{|c|c|c|c|c|c|c|}
\hline \multirow[t]{2}{*}{$\mathrm{dpi}^{\mathrm{a}}$} & \multicolumn{6}{|l|}{ Tissues } \\
\hline & Trachea & Lung & Kidney & Ovary & Testis & Caecal tonsils \\
\hline 1 & $221740^{\mathrm{b}}$ & 110155 & 20667 & 0 & 1548 & 2707070 \\
\hline 2 & 1045981 & 467016 & 23380 & 0 & 807889 & 1339068 \\
\hline 3 & 10878619 & 789780 & 273617 & 0 & 1741502 & $4985837^{\mathrm{c}}$ \\
\hline 5 & 2388166 & 2648971 & 299412 & 2232480 & 115834 & 9278220 \\
\hline 7 & 811372 & 1274234 & 320741 & 380612 & 0 & 2043642 \\
\hline 11 & 18894 & 63984 & 45069 & 274863 & $81326^{\mathrm{c}}$ & $6973352^{c}$ \\
\hline 13 & $109066^{\mathrm{c}}$ & $83666^{\mathrm{c}}$ & 2400 & 2937 & 0 & 2295132 \\
\hline 15 & 0 & 0 & $4762^{c}$ & 0 & 0 & 1713176 \\
\hline 20 & 0 & 0 & 0 & $148762^{c}$ & 0 & $3784095^{\mathrm{c}}$ \\
\hline
\end{tabular}


In this study urinary tract showed marked infection from 1 to $15 \mathrm{dpi}$ and the maximal level of the virus was found on 7 dpi. All kidneys sampled on 20 dpi lacked the viral RNA but the kidney lesions were seen until 20 dpi. Comparison of presence pattern of the virus in kidneys, to trachea and lung showed that presence of the virus more prolonged in the kidneys. These data indicate that IRFIBV32 has nephrotropic properties as many strains of IBV [15]. The results showed that the ovary can support active replication of the IRFIBV32 isolate of IBV between 5 and $13 \mathrm{dpi}$ and virus load appears to peak at 5 dpi. Chousalkar et al. [9] detected T strain of IBV in oviduct from $6 \mathrm{dpi}$ and the viral load appeared to peak between 10 and 14 dpi. IBV RNAs were detected in testes between 1 and $11 \mathrm{dpi}$. Although the viral load in the ovaries was more than testes, the virus replication in the ovaries was overdue in comparison to the testes. Detection of IBV RNA in the testes corroborates findings by others that IBV replicates in the male testicles [11]. In spite of the virus replication in male and female reproductive system, there were no lesions in these organs.

IBV Infection of enteric tissues does usually not manifest clinically but persists for long periods and results in fecal virus shedding. We detected the viral RNA in the caecal tonsils of infected chicken from 1 to $20 \mathrm{dpi}$ and the maximal loads of the virus were on 5 dpi. Comparison of detection of the virus from the caecal tonsils and the other organs showed that the IRFIBV32 isolate can replicate and be detected in the caecal tonsils for a longer time. Naqi et al. [16] isolated Massachusetts serotype vaccine virus from cloacal swabs at 63 dpi. Mahdavi et al. [15] detected the viral antigens in intestine and kidney epithelial cells from 3 to $5 \mathrm{dpi}$. The viral RNA was not detected in the blood of inoculated chickens in this study. No virus was detected in any tissue of the unchallenged group.

The broad distribution of 2, 3-linked sialic acid in different organs explains the pan-tropic nature of IBV in chicken, but it cannot be the only determinant of the pathogenicity because such neuraminic acid is also present on cells that are not infected by IBV. It may be that the sialic acid binding is an initial step requiring further contacts to be made perhaps involving a more specific and less generally distributed secondary receptor [3]. Extended and intermittent shedding of IBV from caecal tonsils is evidence for the potential risk of flock to flock transmission via contamination of personnel or equipment. The probability of continuous excretion of the virus at levels usually below the detection limit of the diagnostic tests, or reactivation in sites such as caecal tonsils or kidneys have been already shown [4].

In conclusions, the results of this study clearly corroborate that IRFIBV32 isolate is capable of distribution and proliferation in different tissues with the longest in the intestine of the experimentally infected chicks. It also is a virulent virus because of its relative long replication period in trachea. The virus titer in the studied tissues had an interesting fluctuation especially in caecal tonsils. Testes and ovaries were the organs that the virus could reactivate without using any chemical. In the last days of the existence in the most tissues the viral titer increased after decreasing and then reached to the zero. It seems that the high titer of the virus is not the only reason for the lesions in the tissues because lesions were present even after disappearing of the virus in the kidneys. In addition, there was no any lesion in the ovaries and testes in spite of the high titer of the virus. More studies are needed to explain more the pathogenesis of the disease.

Acknowledgments The authors extend thanks to the School of Veterinary Medicine, Shiraz University, for providing the necessary facilities and financial support to carry out this study.

\section{References}

1. Adzhar A, Gough RE, Haydon D, Shaw K, Britton P, Cavanagh D. Molecular analysis of the 793/B serotype of infectious bronchitis virus in Great Britain. Avian Pathol. 1997;26:625-40.

2. Aghakhan SM, Abshar N, Fereidouni SRN, Marunesi C, Khodashenas M. Studies on avian viral infections in Iran. Arch Razi Inst. 1994;44:1-10.

3. Ahmed SAM, Zlotowski P, Veits J, Keil GM, Teifke JP. Immunohistochemistry for detection of avian infectious bronchitis virus strain M41 in the proventriculus and nervous system of experimentally infected chicken embryos. Virol J. 2009;6:15. doi:10.1186/1743-422X-6-15.

4. Bhattacharjee PS, Carter SD, Savage CE, Jones RC. Re-excretion of infectious bronchitis virus in chickens induced by cyclosporin. Avian Pathol. 1995;24:435-41.

5. Boroomand Z, Asasi K, Mohammadi A. Pathogenesis and tissue distribution of avian infectious bronchitis virus isolate IRFIBV32 (793/b serotype) in experimentally infected broiler chickens. Sci World J. 2012;. doi:10.1100/2012/402537.

6. Boroomand Z, Razeghian I, Asasi K, Mohammadi A, Hosseini A. Isolation and identification of a new isolate of avian infectious bronchitis virus IRFIBV32 and a study of its pathogenicity. Online J Vet Res. 2011;15(4):366-80.

7. Callison SA, Hilt DA, Boynton TO, Sample BF, Robison R, Swayne DE, Jackwood MW. Development and evaluation of a real-time Taqman RT-PCR assay for the detection of infectious bronchitis virus from infected chickens. J Virol Methods. 2006;138:60-5.

8. Cavanagh D, Gelb J. Infectious bronchitis. In: Saif YM, Fadly AM, Glisson JR, McDougald LR, Nolan LK, Swayne DE, editors. Diseases of poultry. 12th ed. Ames: Blackwell Publishing; 2008. p. 117-35.

9. Chousalkar KK, Cheetham BF, Roberts JR. Detection of infectious bronchitis virus strain N1/88 from the oviduct and feces of experimentally infected vaccinated and unvaccinated hens. Poult Sci. 2010;89:1603-8.

10. Chousalkar KK, Cheetham BF, Roberts JR. LNA probe-based real-time RT-PCR for the detection of infectious bronchitis virus from the oviduct of unvaccinated and vaccinated laying hens. J Virol Methods. 2009; 155:67-71.

11. Farzinpour A, Nili H, Hosseini A. Detection the 4/91 strain of infectious bronchitis virus in testicular tissue from experimentally 
infected rooster by reverse transcription-polymerase chain reaction. Afr J Agric Res. 2009;4(10):1093-6.

12. Feng J, Hu Y, Ma Z, Yu Q, Zhao J, Liu X, Zhang G. Virulent avian infectious bronchitis virus, People's Republic of China. Emerg Infect Dis. 2012;18(12):1994-2001.

13. Grgíc H, Hunter DB, Hunton P, Nagy É. Pathogenicity of infectious bronchitis virus isolates from Ontario chickens. Can J Vet Res. 2008;72(5):403-410.

14. Jackwood MW, Hilt DA, Callison SA. Detection of infectious bronchitis virus by real-time reverse transcriptase-polymerase chain reaction and identification of a quasispecies in the beaudette strain. Avian Dis. 2003;47:718-24.

15. Mahdavi S, Tavasoly A, Pourbakhsh A, Momayes R, Shamseddini M. The immunohistochemistry study of lesions due to avian infectious bronchitis (serotype 4/91) on different tissues in specific pathogen free chicks. J Vet Res. 2007;62(4):97-101.

16. Naqi S, Gay K, Patalla P, Mondal S, Liu R. Establishment of persistent avian infectious bronchitis virus infection in antibodyfree and antibody-positive chickens. Avian Dis. 2003;47:594-601.

17. Reed LJ, Muench H. A simple method of estimating fifty percent endpoint. Am J Hyg. 1938;27:493-7.

18. Vasfi Marandi M, Bozorgmehri Fard MH. Isolation and identification of infectious bronchitis viruses in chickens in Iran. In: Proceedings of the World's Poultry Congress, Montreal, Canada; 2000. p. 20-25. 